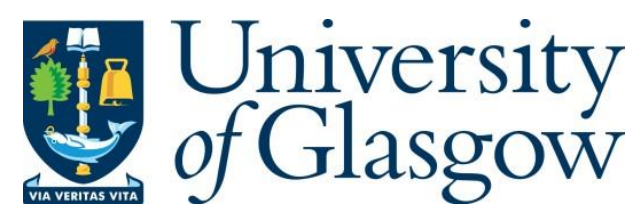

Kelp, C. (2014) No justification for lottery losers. Pacific Philosophical Quarterly, 95(2), pp. 205-217.

There may be differences between this version and the published version. You are advised to consult the publisher's version if you wish to cite from it.

http://eprints.gla.ac.uk/140957/

Deposited on: 16 May 2017

Enlighten - Research publications by members of the University of Glasgow http://eprints.gla.ac.uk 


\title{
No Justification for Lottery Losers
}

\author{
Christoph Kelp
}

\begin{abstract}
Igor Douven has recently developed a challenge for accounts of justification according to which beliefs about lottery losers are never justified. This paper argues that champions of such accounts can rise to Douven's challenge and, what's more, that they can turn Douven's argument around in the sense that they can legitimately take it to provide a vindication of their preferred view.
\end{abstract}

\section{Introduction}

Consider the following three statements:

SUFFICIENCY. If $p$ is very likely to be true given one's evidence, then one has justification to believe that $p$.

Closure. If one has justification to believe each member of a set of propositions $\Gamma$ and one knows that $\Gamma$ entails a further proposition $\varphi$, then one has justification to believe $\varphi$.

No Contradictions. One does not have justification to believe an obvious contradiction.

Individually, each of these three propositions is intuitively highly plausible. As it turns out, however, they are jointly inconsistent. To see this, notice that no matter how high we set the standards for satisfaction of the predicate 'very likely', there will be some fair lottery with exactly one winner such that it is very likely on one's evidence that each ticket will lose. So suppose that a ticket will very likely lose if the chances that it will lose is at least $(n-1) / n$ and let $l$ be a fair lottery one knows to have $n$ tickets and exactly one winner. By SuFFICIENCY, for each ticket in $l$, one has justification to believe that it will lose. By Closure, one has justification to believe that all tickets in $l$ will lose. Since one also knows that $l$ has exactly one winner, 
by a further application of CLOSURE, one has justification to believe that all tickets in $l$ will lose and that exactly one ticket in $l$ will win. However, this is an obvious contradiction and so, by No ContradicTIONS, one does not have justification to believe it. It thus becomes clear that the three claims are jointly inconsistent. This is Kyburg's [1961, 1970] lottery paradox.

No ContRADictions is nearly universally considered to be nonnegotiable (though see Priest 1998). Whatever is wrong with the lottery paradox, it is not No Contradictions. This leaves Closure and Sufficiencr. While early solutions to the lottery paradox have tended to focus on Closure, there are a number of excellent reasons to believe that denying CLOSURE amounts to too high a cost and won't provide a satisfactory solution to the paradox anyway. ${ }^{1}$ If so, we will of course have to give up SufFICIENCY.

It is commonly thought that if we deny SufficIENCY, we will also have to accept an account of justified belief that satisfies the following claim:

No Justification. For each ticket in a given lottery, one does not have justification to believe that it won't win.

However, in a recent paper, Igor Douven [2008] argues that the step from the denial of Sufficiency to the thesis that any adequate account of justified belief must satisfy No Justification may be too quick. More specifically, Douven argues that, for each account of justification that satisfies No Justification (henceforth also 'NJ account'), there is an alternative (henceforth also 'Douven alternative') that has a lot more going for itself than one may initially have thought. In fact, Douven alternatives are attractive enough to settle champions of $\mathrm{NJ}$ accounts with the challenge of having to show their view is indeed preferable.

This paper aims to show that champions of $\mathrm{NJ}$ accounts can rise to Douven challenge and that they can even turn Douven's argument into a vindication of No Justification. In order to achieve this I will first outline Douven's argument (section 2) and deal with some immediate problems on behalf of Douven (section 3). I will then argue that the proper target of the argument is not No Justification but a certain thesis about our epistemic goal Douven takes for granted. Once the problematic thesis has been replaced by a better alternative, it becomes clear that Douven's argument serves to vindicate No JUSTIFICATION rather than present a challenge to it (section 4). 


\section{Douven's argument}

Douven's argument starts from the following thesis about our general epistemic goal:

Truth GoAl. Our epistemic goal consists in amassing a large body of beliefs with a favourable truth-falsity ratio [2008: 205]. ${ }^{2}$

As Douven is quick to point out, TRUTH GoAL is widely accepted among epistemologists and thus appears to be as solid a starting point for his argument as one may hope for. ${ }^{3}$

He goes on to argue for a condition of adequacy for accounts of justification according to which an account of justification is adequate only if it is conducive to our epistemic goal, in the sense that any agent who adopts the account as a policy of belief management is likely to attain or make progress towards attaining our epistemic goal [2008: 208]. This condition of adequacy supports the following principle for comparatively assessing accounts of justification:

Comparison. For any two accounts of justification, $J$ and $J^{\prime}$, that are alike in all other relevant respects, if $J$ is more conducive to our epistemic goal than $J^{\prime}$, then $J$ is preferable to $J^{\prime}$ [2008: 210].

With these theses in play, let's look at Douven's recipe for constructing Douven alternatives to NJ accounts:

Douven Alternative. The Douven alternative, $D A$, to a given $\mathrm{NJ}$ account, $N J$, is an account of justification that 'reads just like [NJ] except that it has an additional clause saying that, given a "sufficiently large" fair lottery with exactly one winner, one is justified to believe of all but one of the tickets that they will lose' [2008: 212].

It is now easy to show that Douven alternatives are preferable to their corresponding NJ accounts. Let $l$ be any fair lottery with $n$ tickets (where $n$ is sufficiently large in the relevant sense) and exactly one winner and let $S$ be any agent. If $S$ adopts $N J$, he will not believe of any ticket that it won't win. As opposed to that, if he adopts its Douven alternative, $D A$, he will believe of $n-1$ tickets that they won't win. Since the lottery has but one winner, it follows that $S$ is guaranteed at least $n-2$ true beliefs and at most two false beliefs. $S$ thus makes better progress towards having a large body of beliefs with a favourable truth-falsity ratio if he adopts $D A$ than NJ. By TRUTH GoAL, $S$ makes better progress towards attaining the epistemic goal if he adopts $D A$ than $N J$. That is to say that $D A$ is more conducive 
to our epistemic goal than $\mathrm{NJ}$ in the sense at issue in COMPARISON. Since $D A$ differs from $N J$ only in that it allows $n-1$ beliefs about lottery losers, $D A$ and $N J$ are alike in all other relevant respects. By Comparison, $D A$ is preferable to NJ. We have a reason to prefer Douven alternatives to $\mathrm{NJ}$ accounts and hence a reason to believe that No JustificATION is false [2008: §4].

Douven considers a number of objections to this argument of which two will be important for present purposes. According to the first, Douven alternatives are unacceptably ad hoc as the crucial extra clause receives no independent motivation. In response, Douven argues that, in the philosophy of science, the reason ad hoc theories are considered unacceptable is that they are thought to prevent us from achieving the goal of science. If there were reason to think that $a d$ hoc theories are beneficial to our achieving the goal of science, there would be no reason to have reservations about them. Moreover, what goes for scientific theories also holds, mutatis mutandis for theories of justification. If so, the ad hocness charge cannot be made to stick [2008: 214].

The second objection claims that Douven alternatives license an unacceptable kind of epistemic arbitrariness. To see this recall that according to Douven alternatives one can justifiably believe of $n-1$ tickets that they will lose. However, there is no more reason for believing of any one set of $n-1$ tickets that each member will lose than there is reason to believe of any other set of $n-1$ tickets that each member will lose. One will have to choose the tickets of which one believes that they will lose arbitrarily. According to Douven alternatives, these arbitrarily chosen beliefs will be justified. However, it is intuitively highly implausible that arbitrarily chosen beliefs could ever be justified. In other words, Douven alternatives entail the counterintuitive:

EPISTEMic Arbitrariness. For some non-empty proper subset $\Delta$ of tickets in sufficiently large lotteries with exactly one winner, arbitrarily chosen beliefs that each member of $\Delta$ will lose can be justified. ${ }^{4}$

By way of response, Douven first points out that we have not seen good arguments that there is a problem with epistemic arbitrariness. He then goes on to argue that in other domains, arbitrariness is compatible with justification. For instance, consider the following 'Lottery Game':

LOtTERY GAME. You are faced with the choice of opening any number of a set of $n$ doors. You also know there is one Euro behind $n-1$ doors 
and nothing behind one door. The goal of the game is to receive money and avoid having to pay money. The rules of the game are that so long as you don't choose to open all doors, you will get all the money you find and you will have to pay one Euro for every door behind which you don't find any money. However, you must not choose to open all doors. If you do, you will get nothing.

The Lottery Game is a practical analogue of beliefs about lottery outcomes. Where in the epistemic case, the goal is to amass lots of true beliefs and avoid false beliefs, in its practical analogue, the goal is to amass monetary gains and avoid losses. Possible beliefs in the epistemic case have possibly opened doors in the practical case as their counterparts. Finally, the constraint that one cannot justifiably believe a contradiction is mirrored by the rule that one must not choose to open all doors. Now, it is not hard to see that, in the Lottery Game, you will be entirely justified to arbitrarily choose to open some nonempty proper subset of doors. In fact, it will be most rational for you to choose to open $n-1$ doors here. Douven's point now is that it would be odd if this kind of arbitrariness were compatible with justification in the practical domain but not in the epistemic domain. In view of this, Douven claims that the onus is on champions of NJ accounts to show that epistemic arbitrariness is incompatible with justified belief. So long they haven't done this, we do not have sufficient reason for accepting any given $\mathrm{NJ}$ account.

\section{Douven Alternatives: Strong and Weak}

Douven alternatives promise us high returns on our epistemic goal compared to their NJ cousins. For any lottery with $n$ tickets, Douven alternatives deliver a minimum of $n-2$ true beliefs at a maximum of two false beliefs, while on NJ accounts, we gain no true beliefs at all. As Douven has argued, given that all else is equal, this means that Douven alternatives are preferable to NJ accounts.

Let's start with an argument that not all else is equal between NJ accounts and Douven alternatives. Unlike NJ accounts, Douven alternatives are incompatible with the conjunction of CLOSURE and the following highly intuitive principle relating justification and evidence:

Necessity. One has justification for believing that $p$ only if $p$ is sufficiently likely to be true given one's evidence (where a proposition is sufficiently likely given one's evidence only if it is more than $50 \%$ likely on one's evidence). ${ }^{5}$ 
To see how this works, let's return to our lottery $l$ with $n$ tickets and exactly one winner. Suppose that $S$ has adopted a Douven alternative and believes of $n-1$ tickets of $l$ that they will lose. Of course, $S$ knows that if all the $n-1$ tickets will lose and there is exactly one winner, the remaining ticket, $i$, will win. Since, according to Douven alternatives, $S$ 's beliefs about $n-1$ tickets are all justified, since $S$ knows (and hence believes justifiably) that exactly one ticket will win, and since $S$ knows that all this entails that $i$ will win, by CLOSURE, $S$ has justification for believing that $i$ will win. However, $S$ also knows that the chances that $i$ wins are $1 / n$. For any $n \geq 2$, the probability that $i$ will win on $S^{\prime}$ s evidence is not larger than $50 \%$. Since there can be no doubt that a lottery is 'sufficiently large' in the sense at issue in Douven Alternative only if it features at least two tickets, by NecEssity, $S$ does not have justification for believing that $i$ will win. We can thus derive a contradiction from a given Douven alternative, Closure and Necessity. One of the three will have to go.

Douven has effectively two options at this stage. He can, robustly, reject or at least restrict either one of Closure and NeCESSITY. Alternatively, he can, concessively, move to a weaker kind of alternative that is compatible with Closure and Necessity. Let's look at the prospects for the robust response first.

Recall that, Douven responded to the ad hocness charge against Douven alternatives by arguing that we have reason to think that $a d$ hocness is a vice of an account of justification only to the extent that we have reason to think that it is detrimental to our achieving the epistemic goal. Since Douven alternatives are not thus detrimental, we have no reason to consider their ad hocness a vice. Now, still in the same spirit, Douven might consider supplementing Douven AlterNATIVES with the following further ad hoc restriction on NeCEsSITY:

Strong Douven Alternative. The strong Douven alternative, $D A_{S}$, to a given $\mathrm{NJ}$ account, $N J$, is an account of justification that reads just like $N J$ except that it has the following two additional clauses: (i) given a sufficiently large fair lottery with exactly one winner, one is justified to believe of all but one of the tickets that they will lose and (ii) one is justified in believing of the remaining ticket that it will win (despite the fact that this is insufficiently likely on one's evidence).

Here too we have no reason to think that ad hocness is a vice because it is conducive to our epistemic goal as we can now reap the benefits of a minimum of $n-2$ guaranteed true beliefs. 
Unfortunately for Douven, there is reason to think that opening the flood gates of ad hocness is not a good idea after all. To see this notice that we can improve on Strong Douven Alternative once more by offering the following alternative ad hoc restriction:

Alternative Alternative. The alternative alternative, $A A$, to a given NJ account, $N J$, is an account of justification that reads just like $N J$ except that it has an additional clause saying that, given a sufficiently large fair lottery with exactly one winner, one is justified in believing of all tickets that they will lose and that there is exactly one winner (despite the fact that this is an obvious contradiction).

In other words, instead of accepting No ConTRADICTIONs and opting for ad hoc restrictions on the extent of justified beliefs about lottery losers one can hold as well as on Necessity, here we simply go for an ad hoc restriction on No Contradictions. Notice that the benefits of adopting alternative alternatives will outweigh the benefits of adopting strong Douven alternatives. After all, we will now be able to reap exactly $n-1$ guaranteed true beliefs. True, we will also have to settle for exactly one false belief. However, on strong Douven alternatives, we incur a $(n-1) / n$ chance of adding two false beliefs to our stock of beliefs and only an $1 / n$ chance of adding no false beliefs. It is not hard to see that, before long, adopting an alternative alternative is virtually certain to be more conducive to our epistemic goal than even strong Douven alternatives. If we have no reason to think that ad hoc restrictions constitute a vice so long as they are conducive to our epistemic goal, there should be no worries about alternative alternatives. On the contrary, given that they are most conducive to our epistemic goal, we should embrace alternative alternatives wholeheartedly.

Before moving on, let me consider a couple of possible moves Douven might make to avoid this result. First, he might object that any account of justification that licenses justified belief in contradictions will do extremely badly when it comes to being conducive to our epistemic goal since anything follows from a contradiction and so, by Closure, any proposition will be justified. However, this objection may be circumvented by simply adding a further ad hoc clause to Alternative Alternative according to which Closure does not hold for beliefs in contradictions. ${ }^{6}$ Second, Douven might venture to restrict COMPARISON in such a way that preferability attaches only to accounts of justification that are significantly more conducive to our epistemic goal. But the question remains how this restriction can be 
motivated. An ad hoc approach will simply not work here (not even by Douven's lights) since the restriction is counter conducive to our epistemic goal. Moreover, it would seem that adopting alternative alternatives will be significantly more conducive to our epistemic goal in the long run. So, it is not even clear that the restriction will do the trick here either.

Reflection on the practical analogue of lottery cases, the Lottery Game, further supports the idea that we should favour alternative alternatives over strong Douven alternatives. Recall that here we have a goal (making as much money as possible) and a set of rules of the game (opening all doors means no money, etc.). This corresponds, respectively, to our goal of amassing a large body of beliefs with a favourable truth-falsity ratio and any independent constraints on justification for belief there may be. Now consider Douven's idea that, in the epistemic case, making ad hoc adjustments to our account of justification is acceptable so long as this increases conduciveness to our epistemic goal. In the practical analogue, this translates into the idea that the rules of the Lottery Game may be modified in any way so long as the modification increases conduciveness to the game's goal, i.e. the maximisation of players' gains and minimisation of their losses. If so, however, there is excellent reason to abandon the rule that corresponds to No Contradictions, according to which one must not choose to open all doors. After all, allowing players to choose to open all doors will be even more conducive to the game's goal.

I am still convinced that No Contradictions is not negotiable, not even in the sense that it is a candidate for further restrictions. As a result, I take the fact that Douven's laissez-faire attitude towards ad hocness would lead us to a restriction on No Contradictions to show that we should avoid this attitude and disallow ad hoc restrictions. By the same token, I'd say that Douven is better off opting for a concessive response to the above incompatibility result.

A concessive response accepts Closure and NecEssity and gives up the idea that Douven alternatives are preferable to $\mathrm{NJ}$ accounts. We might wonder whether anything is left of Douven's argument. Fortunately for Douven, the answer is 'yes'. After all, while NecEsSITY and CLOSURE will prevent us from reaching the returns on our epistemic goal Douven alternatives promise, they still allow for some returns. After all, for sufficiently small $m$, it is sufficiently likely on one's evidence that one of $n-m$ tickets will win the lottery. Compat- 
ibly with Necessity and Closure one can then justifiably believe of $m$ tickets that they will lose. Accordingly we can define the notion of a weak Douven alternative as follows:

Weak Douven Alternative. The weak Douven alternative, $D A_{W}$, to a given $\mathrm{NJ}$ account, $\mathrm{NJ}$, is an account of justification that reads just like $N J$ except that it has an additional clause saying that, given a sufficiently large fair lottery with exactly one winner, one is justified to believe of a sufficiently small non-empty proper subset ${ }^{7}$ of tickets that they will lose.

Notice that weak Douven alternatives will still be more conducive to acquiring true beliefs and avoiding false beliefs than their corresponding NJ accounts. Thus Truth GoAL and Comparison will still favour weak Douven alternatives over their No Justification cousins. ${ }^{8}$ In this way, Douven's challenge for NJ accounts still stands.

\section{Turning Douven's Argument Around}

How, if at all, can champions of No Justification rise to Douven's challenge? Douven suggests one strategy, viz. to provide an argument that EPISTEMIC ARBITRARINESS is really as bad is it intuitively appears to be. While I don't want to deny that this is a worthwhile line to pursue, here I would like to take a slightly different route. In a nutshell, I will first argue that, properly understood, Douven's argument constitutes a reason to think that the following alternative thesis about our epistemic goal is preferable to TRUTH GOAL:

KNOWLEDGE GOAL. Our epistemic goal consists in amassing a large body of beliefs with a favourable knowledge-ignorance ${ }^{9}$ ratio. ${ }^{10}$

I will then show that, once Truth Goal is replaced by KNowledge GoAL, Douven's argument against No Justification will no longer go through. In this way, Douven himself provides champions of No Justification with the means to rise to his challenge. What's more, I will also argue that the KNOwLEDGe GoAL version of Douven's argument serves to vindicate No Justification.

First things first, I will now argue that Douven's argument provides a reason to think that KNOWLEDGE GoAL is preferable to TRUTH GOAL. To see how, notice first that while, in the absence of alternative proposals, TRUTH GoAL may appear intuitively very plausible, once KNOWLEDge GoAl is on the table, it is much less clear that Truth GoAl is indeed the way forward. For starters, KNOwLedge GoAL 
entails TRUTH GoAL in the sense that anyone who attains KNOwLEDGe GoAl will automatically attain TRUTH GoAL. ${ }^{11}$ Moreover, the main difference between the two theses is that in addition to aiming to avoid false beliefs, we should also aim to avoid other beliefs that fall short of knowledge. Given a standard account of knowledge as ungettiered justified true belief (also accepted by Douven), this means that in addition to false beliefs we should also avoid unjustified beliefs and gettiered beliefs. But now notice that both types of belief are few and far between. We don't hold many unjustified beliefs and gettiered beliefs are an even rarer species. Typically, when we form a true belief, we also form a knowledgeable belief. ${ }^{12}$ If so, replacing Truth GoAl by Knowledge GoAl does not make our epistemic goal much harder to attain.

These considerations suggest that we will be hard pressed to argue that there is pre-theoretical reason to favour TRUTH GoAL over KNowledge Goal. ${ }^{13}$ Given that this is so, however, if it can be shown that one view has untoward consequences the other can avoid, this will constitute exactly the kind of evidence on the basis of which we may hope to adjudicate between the two views. Douven himself has already done half of the work. He has provided an argument showing that TRUTH GOAL has at least one untoward consequence: it licenses the counterintuitive EpIstemic Arbitrariness. If, in addition, it can be shown that, once we replace TRUTH GOAL by KNOwLEDGE GOAL, Douven's argument delivers the denial of EPISTEMIC ARBITRARINESS, we can rightly take Douven's argument to show that Truth GoAl has an unwelcome consequence that KNOWLEDGe GoAL avoids. As a result, properly understood, Douven's argument provides a reason to favour KNOWLEDGe GoAl over TRUTH GoAL.

To see that once we replace Truth Goal by KnOwledge GoAl, Douven's argument licenses the denial of EPISTEMIC ARBITRARINESS notice first that, questions of justification aside, it is widely agreed, and according to some even 'intuitively clear' [Williamson 2000: 249], that beliefs about lottery losers fall short of knowledge. With this point in play, let's run Douven's argument. Since any account that licenses EPISTEMIC ARbITRARINESS allows for justified belief about some lottery losers, the account will lead us add to our stock of non-knowledgeable beliefs without adding to our stock of knowledgeable beliefs when adopted. By KnOwLEDGE GoAL, any such account is counter conducive to achieving our epistemic goal. ${ }^{14}$ But now notice that for any account of justification that licenses EPISTEMIC ARbItraRINESS, 
$E J$, we can define an alternative, $N J$, which reads like $E J$, except that it adds No Justification. Unlike EJ, $N J$ will avoid moving us away from our epistemic goal. Since the two accounts are alike in all other relevant respects, by CoMparison, NJ will be preferable to EJ. Thus, with KNOWLedge Goal in place of Truth GoAL, Douven's argument will deliver the result that NJ accounts are preferable to Douven alternatives and any other kind of account that licences EPISTEMIC ARBITRARINESS. Since NJ alternatives entail the denial of EPISTEMIC ARBITRARINESS, the present version of Douven's argument licenses the denial of EPISTEMIC ARBITRARINESs. In consequence, there is reason to believe that, properly understood, Douven's argument provides a reason to favour KNOWLEDGE GOAL over TRUTH GOAL.

It is not hard to see that, with KNowledge GoAl in place of TRUth Goal, Douven's argument against No Justification will no longer go through. The reason for this is that COMPARISON will now favour NJ accounts over Douven alternatives, as we have already seen. Champions of No Justification can thus rise to Douven's challenge.

Recall that I have claimed that, properly understood, Douven's argument vindicates No Justification. Here is why. First, the argument provides a reason to favour KNOWLEDGE GOAL over TRUTH Goal. Once Truth Goal is replaced by Knowledge Goal, however, champions of No Justification can use Douven's argument to provide a reason to think that $\mathrm{NJ}$ accounts are preferable to any alternative type of account-i.e. no matter whether it also licences EPISTEMIC ARBITRARINESs. After all, any such account will allow for at least some justified beliefs about lottery losers. Once we have replaced Truth Goal by Knowledge Goal, it is easy to see that any such account will be counter conducive to our epistemic goal when it comes to beliefs about lottery losers. ${ }^{15}$ Fortunately, for any such account, $J$, we can define an alternative, $N J$, that reads just like $J$, except that it adds No Justification. NJ will avoid the counter conduciveness of $J$ and will therefore, by COMPARISON, be preferable to $J$. In consequence, there is now reason to favour $\mathrm{NJ}$ accounts over any other type of account of justification and No Justification is vindicated.

\section{Conclusion}

It comes to light that champions of No JustificAtion can rise to Douven's challenge. They can rightly claim that, properly understood, 
Douven's argument shows that there is reason to prefer KNOwLedge Goal to Truth Goal and that once Truth Goal is replaced by KNOWLEDGe GOAL, the argument against No Justification will no longer go through. In fact, they can do more than this. They can turn Douven's argument around and argue that, rather than exerting pressure on NJ account, once TRUTH GOAL is replaced by KNOWLEDGE GOAL, the argument serves to vindicate No Justification. They can thus agree that Douven's argument offers some valuable insights, but will be quick to add that these insight are rather different than Douven might have us think. ${ }^{16}$

Centre for Logic and Analytic Philosophy

KU Leuven

\section{Notes}

${ }^{1}$ For summary see Douven [2002: 394-5].

2 Douven also offers a more demanding version of our epistemic goal:

TRUTH GoAL*. Our epistemic goal consists in believing all and only true propositions [2008: 206].

At the same time, Douven is very clear restricting our epistemic goal any further than TRUTH GOAL-specifically to interesting and important truths-would be a mistake. He offers three reasons for this: (i) So doing would introduce a problematic kind of vagueness into the statement of our epistemic goal, leaving us with a multiplicity of goals, one for each agent. (ii) We may become interested in truths that are not of interest for us now. Since we typically cannot predict which truths we will be interested in, we should amass true beliefs regardless of our current interests. (iii) It does not follow that we should devote every free minute of our lives to the acquisition of true beliefs. In fact, that we should not do this is best explained in terms of practical (ir)rationality [2008: 206-7]. In consequence, argues Douven, our epistemic goal is either TRUTH GoAl or TRUTH GoAL*. While Douven leaves open which of the two is the correct statement of our epistemic goal, he shows that this is unproblematic the differences between the two are of no consequence for the purposes of his argument [2008: 207]. For ease of exposition, I will be working with TRUTH GOAL here.

${ }^{3}$ Other prominent champions of Truth Goal or Truth GoAL* include William Alston [1985], Keith Lehrer [1974], Laurence BonJour [1985] and Richard Foley [1992].

4 As Douven also points out, the intuitive implausibility of Epistemic ArbiTRARINESS has also been noted by Dana Nelkin [2000], Kyburg [1997], John Pollock [1987] and Jonathan Vogel [1990].

5 The kind of doctrine associated with Necessity dates back as far as William Clifford's 1877 "The Ethics of Belief". Contemporary champions of Necessity include Earl Conee and Richard Feldman [2004], Susan Haack [1993], Jonathan Adler [2002] and Nishi Shah [2006]. 
A couple of further points are worth noting. First, Douven claims that justification is the kind of standing that turns ungettiered, true belief into knowledge. If so, it is very plausible that to count as sufficiently likely to be true on one's evidence a proposition must be very likely on one's evidence, i.e. the probability of it's being true on one's evidence must be significantly greater than $50 \%$. Second, my argument is compatible with further restrictions on NecEssity. For instance, it is entirely compatible with there being basic beliefs that can be justified even in the absence of supporting evidence. In fact, all that I need here are the relevant instances of NecEssity such as: one has justification for believing that some member of a set of tickets will win the lottery only if this is sufficiently likely on one's evidence.

${ }^{6}$ Notice that it may even be possible to motivate this restriction in a non-ad hoc manner. After all, it would seem that, while it is possible to justifiably believe certains contradictions (e.g. unobvious ones that are believed on the basis of expert testimony), no one can have justification for believing any proposition whatsoever. If so, there may be independent reason to restrict the closure principle to noncontradictions.

${ }^{7}$ A proper subset of tickets is sufficiently small when, compatibly with NecEsSITY and CLOSURE, one can justifiably believe that one of the remaining tickets will win.

${ }^{8}$ Douven also notes that all he needs to get the challenge off the ground is that one can justifiably believe of at least one ticket that it will lose [2008: 212].

9 'Ignorance' here simply means 'belief that falls short of knowledge'.

${ }^{10}$ In parallel with Douven's suggestion for a more demanding alternative to Truth GoAl (n.2), we can imagine a more demanding alternative to KNOWLEDGE GOAL:

KNOWLEDGe GoAL*. Our epistemic goal consists in believing all and only propositions we know.

Notice that Douven's arguments against restricting our epistemic goal further to interesting and important truths (n.2) apply even if our epistemic goal demands knowledge rather than mere true belief. As a result, we may assume that our epistemic goal will be either Knowledge Goal or Knowledge Goal*. At the same time, it will become clear that my argument goes through even if the correct statement of our epistemic goal is the more demanding KNOWLEDGe GoAL*. Accordingly, for present purposes at least, we may leave open the question which of the two statements is correct. Again, for ease of exposition, I will be working with KNOWLEDGE GOAL here.

${ }^{11} \mathrm{Or}$, at any rate, it will do so given the innocent assumption that the content of 'favourable' is at least as strong in KNOWLEdge GoAl as it is in Truth GoAl.

12 It is worth noting that Douven himself accepts the related thesis that justified beliefs will typically also qualify as knowledge [2006: 469-70]. Furthermore, in personal communication, he has expressed his sympathies with the above claim.

${ }^{13}$ In fact, it would seem that, if anything, KNOwLEDGE GoAl has an edge over Truth GoAl on this score. After all, if we had to decide whether we ought to aim for knowledge or rather for mere true belief, it would seem that the more plausible answer is 'knowledge'.

${ }^{14}$ Since the same is true for KNOwLEDGE GoAL*, the argument will go through even if the more demanding statement of our epistemic goal is correct (see n.10). 
${ }^{15}$ Again, the same is true if we opt for the more demanding KNOwLEDGE GoAL* (see n.10).

${ }^{16}$ Acknowledgements. I am indebted to Igor Douven and an anonymous referee for a number of very helpful comments on this paper. This work was funded by a postdoctoral fellowship with Research Foundation - Flanders.

\section{References}

Adler, J. (2002). Belief's Own Ethics. MIT Press, Cambridge/MA.

Alston, W. (1985). Concepts of epistemic justification. The Monist, 68:57-89.

BonJour, L. (1985). The Structure of Empirical Justification. Harvard University Press, Cambridge/MA.

Clifford, W. (1877/1999). The ethics of belief. In Madigan, T., editor, The Ethics of Belief and Other Essays. Prometheus Press, Amherst/MA.

Conee, E. and Feldman, R. (2004). Evidentialism: Essays in Epistemology. Oxford University Press, Oxford.

Douven, I. (2002). A new solution to the paradoxes of rational acceptability. British Journal for the Philosophy of Science, 53:391-410.

Douven, I. (2006). Assertion, knowledge, and rational credibility. Philosophical Review, 115:449-485.

Douven, I. (2008). The lottery paradox and our epistemic goal. Pacific Philosophical Quarterly, 89:204-25.

Foley, R. (1992). Being knowing incoherent. Noûs, 26:181-203.

Haack, S. (1993). Evidence and Inquiry. Towards Reconstruction in Epistemology. Blackwell, Oxford.

Kyburg, H. (1961). Probability and the Logic of Rational Belief. Wesleyan University Press, Middletown/CT.

Kyburg, H. (1970). Conjunctivitis. In Swain, M., editor, Induction, Acceptance and Rational Belief. Reidel, Dordrecht.

Kyburg, H. (1997). Probabilistic acceptance. In Proceedings of the Thirteenth conference on Uncertainty in artificial intelligence, UAI'97, pages 326-33. 
Lehrer, K. (1974). Knowledge. Clarendon Press, Oxford.

Nelkin, D. (2000). The lottery paradox, knowledge, and rationality. Philosophical Review, 109:373-409.

Pollock, J. (1987). Defeasible reasoning. Cognitive Science, 11:481-518.

Priest, G. (1998). What is so bad about contradictions? The Journal of Philosophy, 95:410-26.

Shah, N. (2006). A new argument for evidentialism. The Philosophical Quarterly, 56:481-98.

Vogel, J. (1990). Are there counterexamples to the closure principle? In Roth, M. and Ross, G., editors, Doubting: Contemporary Perspectives on Skepticism. Kluwer, Dordrecht.

Williamson, T. (2000). Knowledge and Its Limits. Oxford University Press, Oxford. 